\title{
Productivity Improvement using Lean Concept in Automotive Welding Fixture Manufacturing Industry
}

\author{
Karikalan R, Sreeharan B N, Akilan S, Rallish Rahuman Khan J
}

\begin{abstract}
In today's global marketplace, especially the Own Equipment's Manufacturer (OEM), manufacturing automotive components must be more competitive to compete with competitors, where production cost is an important concern. To increase the productivity and to decrease the production cost, lean thinking can be applied which in turn enables the company to survive in today's competitive world and to have competitive edge. In one of the Automotive Welding Fixture Manufacturing industry, which manufactures Body in White (BIW), some of the problems were identified which reduces the productivity and increases the production cost. Even though trial and error methods based on the experience were used to address the abovementioned problems, a systematic lean thinking if applied will produce more effective results. In this aspect, some of the lean tools viz. 4M, bin system and KANBAN system were applied in this work to eliminate / reduce the implications of these problems. By implementing these lean concepts, the welding fixture manufacturing company saves around 33 hours approximately per week which inturn produces a profit of around Rs. 20,960/per week.
\end{abstract}

Keywords - Lean thinking, productivity improvement, welding fixtures, KANBAN, Bin system, 4M

\section{INTRODUCTION}

To survive in today's global market, it becomes necessary to produce a high-quality product within the given time with profit, it becomes important to adopt the methodologies like Lean Thinking. Some of the problems identified in various sectors of an Own Equipment Manufacturer (OEM) manufacturing automotive components which affects the profit of the industry, suitable lean tools for the problem is to be identified through literature surveys and solutions are to be developed for solving the problems identified.

This paper describes few such problems and discusses the tools and solutions required for solving the identified problems.

\section{LITERATURE REVIEW}

Jones, et. al. (1991) found that Lean production removes the wastes "Muda". Muda is Japanese word that means waste, specifically any human activity which absorbs resources but creates no value. Lean thinking is a systematic

Revised Manuscript Received on July 18, 2019.

Karikalan R, Deputy Manager - NPD, Rajsriya Automotive Industries (P) Ltd. Hosur, India. (E-mail: rkk1978@gmail.com)

Sreeharan B N, Assistant Professor - II (Mechanical), Kumaraguru College of Technology, Coimbatore, India. (E-mail: sreeharans@gmail.com)

Akilan S, UG Scholar - Mechanical, Kumaraguru College of Technology, Coimbatore, India. (E-mail: akilan.16me@kct.ac.in)

Rallish Rahuman Khan J, UG Scholar - Mechanical, Kumaraguru College of Technology, Coimbatore, India. (E-mail: rallish.16me@kct.ac.in) approach for identifying and eliminating wastes, in a manufacturing environment, piles of excess product of work - In - Progress (WIP) waiting in queues are a waste. Jeffry M Carr (2005) in his research paper claims that consumption of the floor space and increasing the time a product takes to flow through the plant can be reduced by lean thinking. Madhulbala Ranuniyar (2007) in his paper states that lean manufacturing is a systematic approach to process improvement. It is based on identifying and reducing wastes coupled with continuous improvement. Narasimhan et al. (2006), Al-Aomar, (2006), lists and gives the details about the types of wastes that lean focuses on. AzaBadurdeen (2007) discussed that there were many people who trust to use the tools in lean manufacturing without understanding the meaning of them. They eventually failed. But there are number of places this system is working well. The complete elimination of waste is the target of the system. This concept is vitally important today since in today's highly competitive world there is nothing we can waste. Lean manufacturing defines the value of a product (or) service with the customer point of view. Hudlimohd. Rameez, K. H. Inamdar (2010) discussed that many organizations are now a day's interested to adopt lean manufacturing strategy that would enable them to complete in this competitive globalization market. In this respect, it is necessary to assess the implementation of lean manufacturing in different organizations so that the important best practices can be identified. Jenifer tice, et. al (2005) discussed that Lean thinking aims to produce high quality products and services at the lowest cost with maximum customer responsiveness and Lean accomplishes this through systematic identification and elimination of waste, with the emphasis on continuous improvement and employee involvement. Kazuhiro Yamashita (2004) focused on how the business consultants execute organizational change such as "Lean Manufacturing Implementation Process' in the real business world from a corporate training stand point. Mohammad Talehani (2010) discussed that the lean manufacturing as the combination of directions and a culture which managers could draw the guide lines for achieving benefits through that. Two basic lines of lean manufacturing are "respect to the workforce" and waste "elimination". H. William Dettmer (2008) discussed that Lean Manufacturing (LM) evokes images of efficiency and minimizing unnecessary costs, an attractive value for many companies. Yu Cheng 


\section{PRODUCTIVITY IMPROVEMENT USING LEAN CONCEPT IN AUTOMOTIVE WELDING FIXTURE MANUFACTURING INDUSTRY}

Wong, Kuan Yew Wong, Anwar Ali (2009), discussed the 14 key areas of Lean manufacturing namely, scheduling, inventory, material handling equipment, work processes, Quality, employees, lay out-suppliers, customers, safety and ergonomics, product design, management and culture, tools and techniques. Parag Katira and Narkhede (2005) emphasized on targeting the oldest evil of any organization, (i.e.) waste. It is also banks on radical, continuous incremental improvisation. It provides an organization high return investment, shorter lead times, better service, lesser cost, and improve quality.

\section{PROBLEMS IDENTIFIED}

Details of the problems identified are discussed below

\section{A. Rejection of parts}

Following table shows the details about the rejected parts in a BIW welding fixture. Total machined parts are 3000. Among 3000 parts machined, 200 parts got rejected.

Table I. Rejection Details

\begin{tabular}{|l|l|l|}
\hline \multicolumn{1}{|c|}{ Details } & QTY & \multicolumn{1}{c|}{$\%$} \\
\hline DIRECT OK & 2600 & $87 \%$ \\
\hline REWORK & 200 & $6 \%$ \\
\hline REJECTION & 200 & $7 \%$ \\
\hline
\end{tabular}

\section{B. $4 W$ \& $1 H$ Analysis}

By using $4 \mathrm{~W} \& 1 \mathrm{H}$ analysis, by brainstorming session, data are collected and segregated to find out WHAT the reason is and HOW the rejections have occurred. In this work, $4 \mathrm{~W} \& 1 \mathrm{H}$ analysis used which is described below.

- WHO is the responsible for this problem?

This is used to find out the source of the problem or the place where it originates. By asking above question, it is found that engineers in in-house and Vendor Development sourcing (VDS) were the responsible.

- WHERE did this problem occur?

This represents the place the problem identified. Here, in BIW Welding fixture Assembly line in in-house is the place where the problem occurred.

- WHEN did this problem occur?

It represents the time when the problem occurred in the production line. It is occurred while assembling the machined part component in welding fixture assembly line.

- WHO noticed this problem?

It gives the personnel who noticed the problem. Here, associates doing the inspection activity noticed the problem.

- HOW can this problem be solved?

It provided the solution for the identified problems. In this work, it can be solved by applying lean thinking.

\section{Details about the part got rejected:}

\section{Part Name :}

PANEL MATTING PLATE

Part No. :

Project Name : 200A 216H 70001008

Cost of Each Part :

ALH-1

Approximate loss in terms of cost for the rejected parts will be $(200$ X Rs. 250$)=$ Rs. 50,000/-, which includes non value added activities as associated with the production of that part.

\section{Pareto Analysis}

After identifying the reasons for rejection, by Pareto Analysis as shown in Fig. 1, reasons for rejection are prioritized. Table 1. gives the details

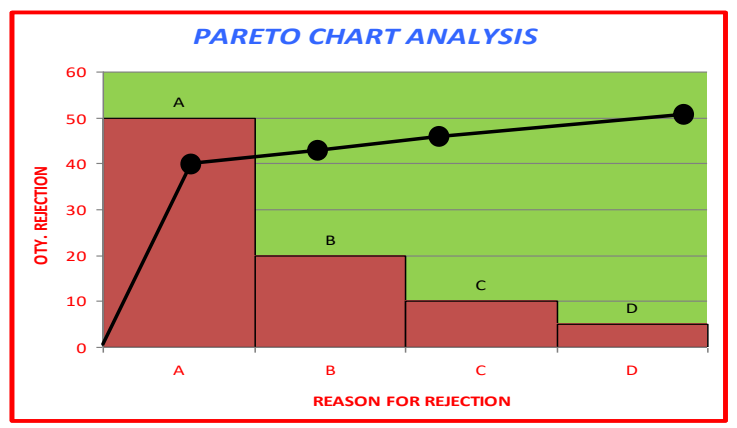

Fig. 1 - Pareto Chart

Table II.Classification of Rejection

\begin{tabular}{|c|c|l|}
\hline S. No. & Quantity & \multicolumn{1}{|c|}{ Reasons for Rejection } \\
\hline A & 50 & $\begin{array}{l}\text { Panel not mating in BIW Welding } \\
\text { fixture assembly }\end{array}$ \\
\hline B & 20 & Open out of weld area \\
\hline C & 10 & Geometrical dimensions variations \\
\hline D & 5 & $\begin{array}{l}\text { Required parameters not reached } \\
\text { while testing }\end{array}$ \\
\hline
\end{tabular}

From the above Pareto analysis, it is identified that panel not mating is the major reason, which is to be solved, to reduce the production cost.

\section{E. Cause \& Effect Diagram}

Further, by using Cause and Effect Diagram as shown below in Fig. 2, the reasons for problem identified were found out.

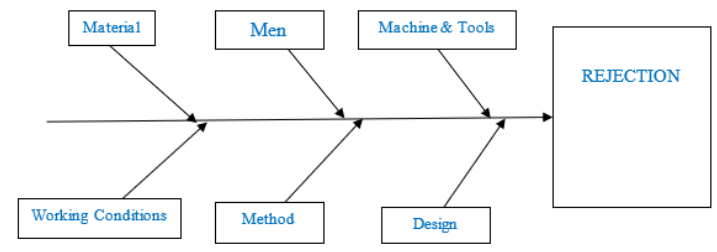

Fig. 2 - Cause and Effect Diagram

\section{F. Identified reasons are for the problem}

1. Difficulty in identification of the raw materials in DXF Format

2. Failing to perform the de-burring operations

3. Difficulty in retrieving machine or fabricated parts / components

\section{G. Identification of the raw materials in DXF format}

Identification of the raw materials obtained as shown in Fig. 3 from the vendors are very difficult as there were no relevant documents related to Data X-Change Format (DXF) attached with. This is considered as one of the important problems, due to this, there is delay in moving to the next operations occurs, which ends up in in-process inventory. 
Since the raw materials for different stages get mixed because of the above-mentioned problem there occurs a delay in separating the raw materials which leads to the wastage of time of about $8 \mathrm{hrs}$. per week.

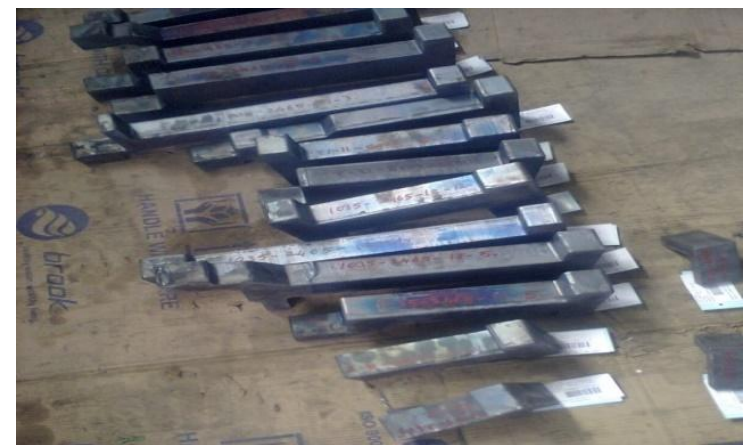

Fig. 3. Raw Materials Obtained From Vendors

\section{H. Failing to perform the de-burring operations:}

De-burring operations are to be carried out for every part as shown in Fig. 4 in the assembly. As there is no follow- up for checking these operations, sometimes this operation is not performed. This results in poor quality, injury to the employees who are handling these parts and which in turn indirectly affects the productivity. As compared to other stages, lack of this process, affects the other processes both directly and indirectly. Because of this, total wastage of time is $6 \mathrm{hrs}$. per week approximately.

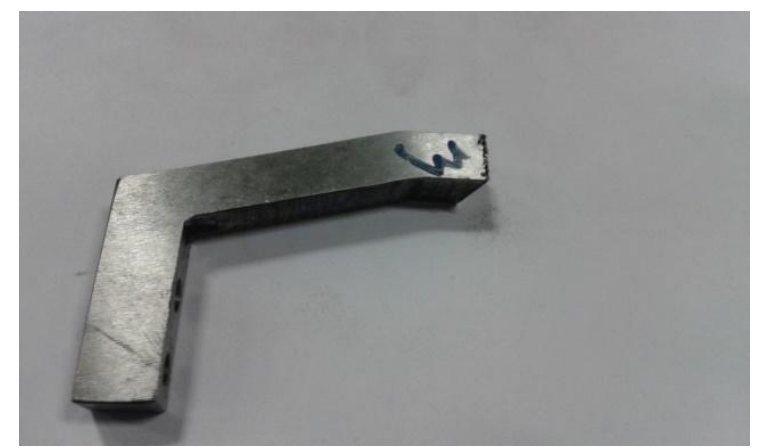

Fig. 4 Component where de-burring operation is not performed

I. Difficulty in retrieving machine or fabricated parts / components

Project Tool Unit Detail (PTUD) checking is very important task in in-house, with respect to getting the raw materials (DXF) from vendor's (VDS). Till the final assembly it is to be checked, ensured and segregated as per the PTUD Numbers otherwise it will result in time delay. PTUD is also required to manufacture when the customer requests for a specific machined (or) fabricated parts. The following fig. 5 shows the parts with missed PTUD number. (2-115-8-2 PTUD NUMBER) which results in total wastage of time is $24 \mathrm{hrs}$. per Week

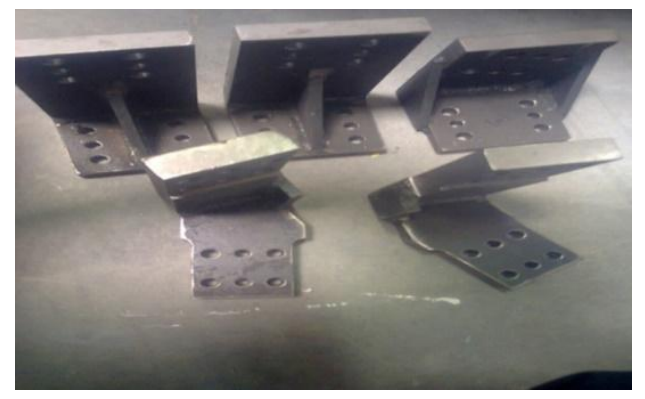

Fig. 5 Parts with missing (PTUD) numbers

\section{J. Solutions identified}

By $4 \mathrm{~W}$ and $1 \mathrm{H}$ analysis, as discussed earlier, reasons for the problems and solutions obtained thereby, which is consolidated and listed below in the table.

Table III.Reasons for the problem identified and its solution

\begin{tabular}{|l|l|l|}
\hline $\begin{array}{l}\text { REASON FOR THE } \\
\text { PROBLEM }\end{array}$ & SOLUTION & $\begin{array}{l}\text { Time } \\
\text { Saved / } \\
\text { Per week } \\
\text { (Hrs.) }\end{array}$ \\
\hline $\begin{array}{l}\text { Difficulty in } \\
\text { identification of the } \\
\text { raw materials in DXF } \\
\text { Format }\end{array}$ & $\begin{array}{l}\text { By implementing } \\
\text { BIN system for easy } \\
\text { identification }\end{array}$ & 8 \\
\hline $\begin{array}{l}\text { Failing to perform the } \\
\text { de-burring operations }\end{array}$ & $\begin{array}{l}\text { By following } \\
\text { KANBAN system }\end{array}$ & 6 \\
\hline $\begin{array}{l}\text { Difficulty in retrieving } \\
\text { machine or fabricated } \\
\text { parts / components }\end{array}$ & $\begin{array}{l}\text { By punching the } \\
\text { PTUD No. on the } \\
\text { parts }\end{array}$ & 24 \\
\hline
\end{tabular}

\section{RESULTS AND DISCUSSIONS}

Solutions for the problem as given above and the corresponding results obtained are discussed below

\section{A. Identification of the raw materials in DXF format}

To reduce the time delay due to difficulty in identification of raw materials in DXF format, BIN system as shown in Fig. 6 was implemented. Accordingly, separate bins are used in inventory for storing the raw materials according to their order of usage. Because of this, workers were able to identify the materials easily even though there is a change in shift. By implementing this method 8 hours in the production process is saved which leads to increase in production with profit.

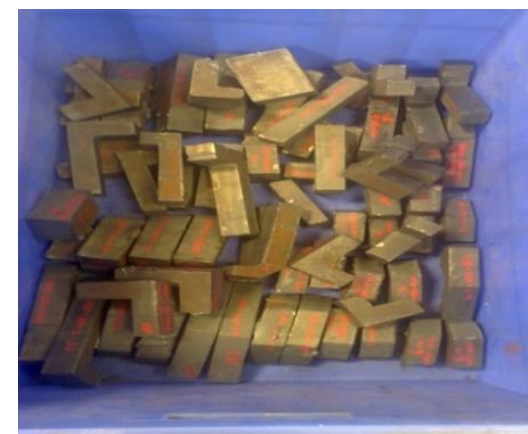

Fig. 6. Implementation of Bin System

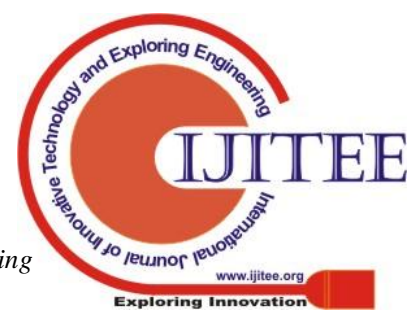




\section{PRODUCTIVITY IMPROVEMENT USING LEAN CONCEPT IN AUTOMOTIVE WELDING FIXTURE MANUFACTURING INDUSTRY}

Approximate calculated manpower cost involved in the process and subsequent cost savings incurred is detailed below

Manpower cost / hr. :

Rs. 220/-

Total saving in manpower cost :

8 hrs x Rs. 220/-

The total savings/week :

Rs. 1760/-

\section{B. Failing to perform de-burring operations:}

To improve the product quality and to avoid injury to the employee, the parts machined to be de-burred immediately. Responsibility for performing de-burring operations is given to the employees who machines the parts itself. To ensure this KANBAN system is updated.
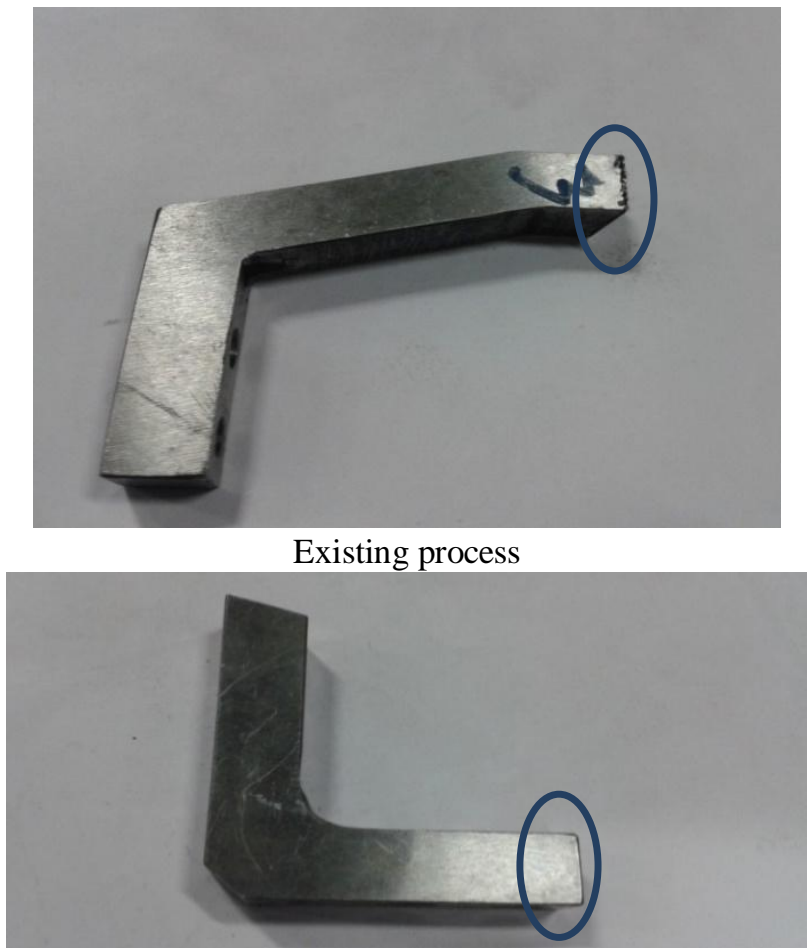

Modified process

Fig. 7. Existing and Modified Process after performing the de-burring operations

Performed de-burring operations after the updation of KANBAN system is shown in the above Fig. 7. By doing the de-burring operations as discussed earlier, resulted potential cost saving is given below. Manpower cost and other direct and indirect cost involved is calculated approximately as Rs. 1000

Cost / hr. :

Rs. $1000 /$

Total saving in cost :

6 hrs x Rs. 1000/-

The total savings/week : Rs. 6000/-

C. Difficulty in retrieving machine or fabricated parts / components:

In order to avoid the difficulty in retrieving machine or fabricated parts or components, PTUD No. is punched on the parts as shown in the fig. 8 .

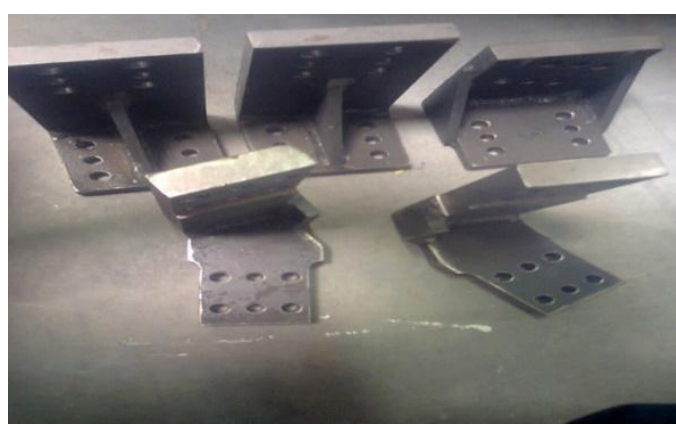

Existing process

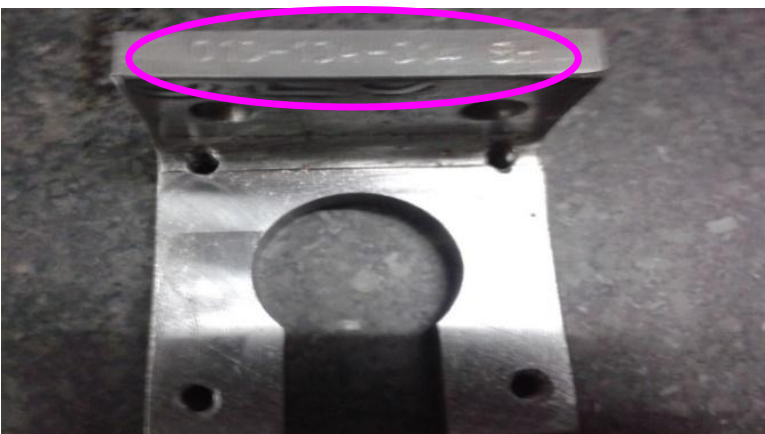

Modified process

Fig. 8. Existing and Modified Process showing punched PTUD No.

By doing so, total savings in cost is detailed below.

Manpower cost / hr. : $\quad$ Rs. 550/-

Total saving in manpower cost : $\quad 24 \mathrm{hrs} x$ Rs. 550/-

The total savings/week : Rs. 13200/-

\section{Total Savings:}

After implementing the lean thinking for solving the problem identified total savings in time and as well as in cost is consolidated and given below in the Table 3 .

Table IV. Total Savings in Time and Cost

\begin{tabular}{|l|c|c|}
\hline \multicolumn{1}{|c|}{ REASON FOR THE } & $\begin{array}{c}\text { Cost } \\
\text { Paved } \\
\text { / Per } \\
\text { week } \\
\text { (Rs.) }\end{array}$ \\
\hline $\begin{array}{l}\text { Difficulty in identification of } \\
\text { the raw materials in DXF } \\
\text { Format }\end{array}$ & 8 & 1760 \\
\hline $\begin{array}{l}\text { Failing to perform the de- } \\
\text { burring operations }\end{array}$ & 6 & 6000 \\
\hline $\begin{array}{l}\text { Difficulty in retrieving } \\
\text { machine or fabricated parts / } \\
\text { components }\end{array}$ & 24 & 13,200 \\
\hline Total Savings & 38 & 20960 \\
\hline
\end{tabular}

\section{CONCLUSION}

Lean thinking through lean tools was successfully implemented to reduce the time and thereby the production cost which inturn lead to reduction in product cost and increase in profit. After the identification of the problem by

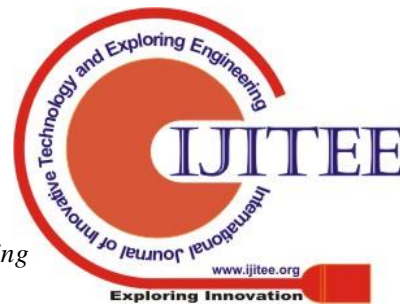


using the lean tools, solutions were successfully implemented. A total of 38 hours of production time is saved with a cost of Rs. 20,960 per week. This will result in cost savings of Rs. 1,089,920 per annum. This enables the industry to compete more with their competitors.

\section{REFERENCES}

1. Aza Badurdeen, Lean Manufacturing Basics, 2007

2. Carr M, Jeffrey. (2005). Value stream mapping of a rubber products manufacturer.

3. Cheng Wong, Yu \& Yew Wong, Kuan \& Ali, Anwar. (2009). A Study on Lean Manufacturing Implementation in the Malaysian Electrical and Electronics Industry. European Journal of Scientific Research. 38(4).

4. Hudli Mohd Rameez, K. H. Inamdar - Areas of Lean Manufacturing for Productivity Improvement in a Manufacturing Unit, World Academy of Science, Engineering and Technology 45(2010)

5. Jones, D.T., Womack, J.P., and Roos, D. (1991) The machine that changed the world: The story of lean production, Harper Perennial, New York.

6. Kazuhiro Yamashita (2004) Implementation Of Lean Manufacturing Process To Xyz Company In Minneapolis Area

7. Madhubala Rauniyar (2007) Value Stream Mapping at XYZ Company

8. Narasimhan, R., Swink, M., \& Kim, S.W. (2006). Disentangling leanness and agility: An empirical Investigation. Journal of Operations Management, 24, pp. 440-457.

9. Taleghani M (2010), "Key factors for implementing the lean manufacturing system," Science (80-.)., vol. 6, no. 7, pp. 287 291

10. Tice J, Ahouse L, and Larson T, "Lean production and EMSs: Aligning environmental management with business priorities," Environ. Qual. Manag., vol. 15, no. 2, pp. 1-12, 2005.

11. William Dettmer, H. (2008). Beyond Lean Manufacturing: Combining Lean and the Theory of Constraints for Higher Performance. 